
\title{
25 Research Soure \\ Relationship Between Workplace Bullying, Spirituality And Job Burnout In Pediatric Nurses: A Cross-Sectional Study
}

\section{Ying Fan}

Xiang Yang No.1 People's Hospital

Mi Cao

Wuhan University

Yumei Zhou

Xiang Yang No.1 People's Hospital

Peng Duan

Xiang Yang No.1 People's Hospital

Limin Xing ( $\boldsymbol{\nabla}$ 2816405103@qq.com )

Xiang Yang No.1 People's Hospital

\section{Research Article}

Keywords: Workplace bullying, Job burnout, Workplace Spirituality, Pediatric Nurse

Posted Date: February 25th, 2022

DOI: https://doi.org/10.21203/rs.3.rs-1348279/v1

License: (c) (i) This work is licensed under a Creative Commons Attribution 4.0 International License. Read Full License 


\section{Abstract}

Background: Workplace bullying threatens public health as a serious social problem globally. The nursing field is one of the hardest hit areas where bullying is breeding. The purpose of this study was to investigate the relationships and pathways between workplace bullying, workplace spirituality and job burnout in Chinese pediatric nurses.

Methods: The sample of this cross-sectional study consists of 402 pediatric nurses who worked at six hospitals in Hubei Province, China. The data were collected using a sociodemographic data questionnaire, Negative Acts Questionnaire-Revised, Maslach Burnout Inventory-General Survey and Workplace Spirituality Scale. The model was tested using path analysis techniques within structural equation modeling.

Result: The research data supported the proposed model. Workplace bullying had positive and direct effects on the burnout of pediatric nurses. Workplace spirituality partially mediated the relationship between workplace bullying and burnout.

Conclusions: Workplace spirituality plays an important role in correctly recognizing and evaluating work stressors. Workplace spirituality may reduce the incidence of bullying and burnout in pediatric nurses. Nursing managers should first acknowledge the existence of workplace bullying. Next, they need to consider and cultivate the workplace spirituality of pediatric nurses, with the aim of creating a healthy working environment and ensuring the stability of the nursing team.

\section{Background}

Bullying in the workplace has been defined as "a situation where someone is subjected to social isolation or exclusion, his or her work and efforts are devalued, he or she is threatened, derogatory comments about him or her are said behind his or her back, or other negative behavior aimed to torment, wear down, or frustrate occur"[1]. Bullying in the workplace has become a serious social problem ever since workplace competition increased in the $21^{\text {st }}$ century, and bullying in the nursing profession is becoming more frequent[2]. As early as 100 years ago, bullying already existed in the nursing profession. In 1909, the "New York Times" published an article about nursing managers who abused their powers to openly persecute nurses, which aroused people's attention to workplace bullying in the nursing profession[3]. Today, bullying is not a new issue. Although bullying has been a well-researched topic in the past 30 years, it is unfortunately still widespread in the nursing profession.

Evidence showed $65 \%$ of nursing professionals in the USA observed lateral violence among coworkers[4]. A cross-sectional survey of workplace bullying by clinical nurses showed that $39.59 \%$ of nurses were bullied in Beijing, China[5]. These statistics highlight the severity of workplace bullying in the nursing industry. 
Pediatric nurses care for infants and young children who have not yet fully developed their language functions. Consequently, it is more difficult for pediatric nurses to communicate effectively with children and their caregivers. In addition, particular characteristics of the hospital environment may lead to adverse reactions in children, such as crying and fear[6]. At the same time, when a child is seriously ill, it may be a devastating blow to the entire family. The family of the child has experienced tremendous changes, such as destruction of family life and forced separation from important family members[7]. Caregivers of children are prone to anxiety, depression, paranoia, emotional agitation and other negative emotions[8], and may even act aggressively to nurses with complaints, insults, and beatings[9]. Chen's survey showed that 215 of 304 pediatric nurses had experienced workplace violence, with an incidence rate of $70.7 \%[10]$. Pediatric nurses suffer more severe workplace bullying than nurses in other departments in China[11].

Studies have shown that continuous exposure to stressful environments caused by workplace bullying can increase the risk of hypertension and heart disease in nurses[12]. Workplace bullying causes not only physical problems (such as physical discomfort, fatigue and angina)[13], but also mental health problems (such as anxiety, depression, and post-traumatic stress disorder)[14]. Workplace bullying also leads to job-related problems, such as decreased job satisfaction in nurses, poor job performance, impaired working relationships, job burnout, and increased turnover tendency[2, 15]. For example, it causes nurses to lose professional confidence, affects the quality of nursing services, and increases the factors that negatively affects patient safety[16]. In addition, it not only affects victims directly, but also affects people who have witnessed bullying incidents, as they may also experience similar physical discomfort and psychological barriers[2]. In short, workplace bullying increases the mobility of nurses and hinders the development of the organization.

In order to improve China's population structure and actively respond to an aging population, China promoted a new optimized 'three-child' family planning policy on May 31, 2021, which allows a couple to have three children. Given the implementation of this policy, the demand for pediatric nurses will further increase. Therefore, improving the morale of pediatric nurses and reducing the turnover rate is of great significance to team stability.

The transactional theory of stress was proposed by Lazarus and Folkman in 1984 [17], and it is a pressure theory based on evaluation. They believe that pressure is the interaction between people and the environment. The source of pressure is based on the subjective perception of the individual. Pressure will only occur when the situation is beyond the resources of the individual. When assessing a situation involving human and environmental interactions, there are two important evaluation processes. (1) The primary evaluation is to assess the situation faced, to judge whether it represents a threat to the individual. (2) The secondary evaluation is based on the individual's own internal and external coping resources. The primary and secondary evaluations are combined to determine whether the environmental interaction is of great significance to the individual. After determining whether the pressure is obstructive or challenging, the individual responds through cognitive or behavioral changes[18]. 
Based on the transactional theory of stress, we believe that pediatric nurses will regard workplace bullying as a source of pressure, and it is an important factor leading to job burnout in nurses[19, 20]. If the individual can correctly recognize or evaluate the pressure, the negative impacts of the pressure on the individual can be reduced. Workplace spirituality is about finding positive meaning in work and a feeling of connectedness expressed in interrelationships between colleagues and a healthy workplace atmosphere[21]. It can have a significant impact on an individual's cognition and pressure evaluation, which is conducive to positively strengthening their impulse to counter pressure, stimulating their work efforts and increasing work enthusiasm. At the same time, inhibiting the negative impacts of obstructive pressure weakens the employees' sense of job burnout and reduces turnover rate[22]. Employees with a high level of workplace spirituality can experience extraordinary meaning in their work. The sense of interconnection that the work brings to themselves, others and the organization will affect the employees' cognitive behavior[23]. Studies have shown that workplace spirituality is positively correlated with the employees' degree of job satisfaction and organizational harmony, and negatively correlated with work pressure and job burnout[24, 25].

In view of these correlations, we constructed the theoretical model of this research study, as shown in Figure 1, based on the transactional theory of stress and previous related research studies. The hypotheses of our research are as follows:

Hypothesis 1: Workplace bullying is positively and directly related to burnout.

Hypothesis 2: Workplace bullying is negatively and directly related to workplace spirituality.

Hypothesis 3: Workplace spirituality is negatively and directly related to burnout.

Hypothesis 4: Workplace spirituality has a mediating effect between workplace bullying and burnout.

\section{Methods}

\section{Study design and participants data collection}

A web-based cross-sectional study was conducted among pediatric nurses in June 2021. The target participants of the study were pediatric nurses working in six hospitals located in Hubei Province, China. The inclusion criteria were as follows: (1) Nurses who had obtained professional registration; (2) Nurses who had worked in pediatrics departments for more than 6 months; (3) No mental illness in the past or present; (4) An ability and willingness to participate in this study. Pediatric nurses who couldn't participate in this study due to holidays, personal leave or physical reasons were excluded.

\section{Data collection}

The researchers explained the purpose of the study to the nursing department staff at six hospitals, requested approval to perform the study, and collected data from the six approved hospitals. The directors of the nursing departments were requested to distribute the links of the internet survey to the 
pediatric nurses in each hospital, along with an explanatory statement, consent forms, and four questionnaires. For the anonymous surveys, we followed all relevant guidelines and regulations, and obtained informed consent from all the participants. The participants took approximately $20 \mathrm{~min}$ to complete the questionnaire.

\section{Ethical considerations}

All data in this research were anonymous, stored in a password-protected computer and only available to members of the research team. Researchers were forbidden from disclosing the personal information of participants to ensure their privacy. The study was approved by the Ethics Committee of Xiangyang No 1 People's Hospital Affiliated to Hubei University of Medicine (NO. 2020KY033-05).

\section{Study tools}

\section{Demographics questionnaire}

The demographic characteristics of our self-designed questionnaire covered: gender, age, marital status, years of experience, employment type, education, title and shift pattern.

\section{Workplace Bullying}

The Chinese version of the Negative Acts Questionnaire-Revised (NAQ-R), originally developed by Einarsen[26], was translated into Mandarin Chinese by Xun et al.,[27] and used to assess the level of workplace bullying in nurses. The questionnaire contained 22 items that measured three dimensions including work-related bullying, person-related bullying and organization-related bullying. Each item was scored ranging from 1 (never) to 5 (every day), with higher scores indicating more serious workplace bullying. The scale content validity index CVI was 0.919 , the internal consistency coefficient was 0.915 , and the test-retest reliability was 0.883 [27].

\section{Workplace Spirituality}

The Workplace Spirituality Scale (WSS) developed by Ke et al.,[28] was used to assess the level of workplace spirituality in nurses. The questionnaire contained 27 items that measured three dimensions including meaningfulness of work, team spirit and organizational values. Each item was scored ranging from 1 (strongly disagree) to 4 (strongly agree). A higher score indicates higher levels of workplace spirituality. The internal consistency coefficient of scale was 0.90 , and the test-retest reliability was $0.77[28]$.

\section{Job Burnout}

The Chinese version of the Maslach Burnout Inventory-General Survey (MBI-GS), originally developed by Maslach[29], was translated into Mandarin Chinese by Li \& Shi[30] and used to assess the level of job burnout in nurses. The questionnaire contained 15 items that measured three dimensions including emotional exhaustion, depersonalization or dehumanization, and low levels of personal accomplishment. 
Each item was scored ranging from 0 (never) to 6 (very frequently). A higher score indicates higher levels of job burnout. This tool has previously demonstrated acceptable internal consistency (Cronbach's a = 0.732 ) and predictive validity in a sample of nurses[31].

\section{Data analysis}

We conducted descriptive statistics, correlations and multiple regression by using IBM SPSS v23.0. Chisquare and $t$ tests were used to compare the differences in pediatric nurses using the scores for workplace bullying, workplace spirituality, and job burnout. The data were normally distributed in the study, thus Pearson's correlation coefficient ( $r$ ) was used to conduct correlation analysis for the study variables. Multiple linear regression analysis was used to explore the independent factors of job burnout.

The testing of the hypothesized model was conducted using AMOS version 23.0. Structural equation modelling with maximum likelihood estimation was used to test the fit between the data and the hypothesized model. The following indices were used to test the hypothesized mediational models[32]: Chi-square $\left(x^{2}\right)$ and the Chi-square/degrees of freedom ratio $\left(x^{2} / d f\right)$, Root Mean Square Error of Approximation (RMSEA) $\leq 0.08$, Comparative Fit Index $(\mathrm{CFI}) \geq 0.09$ and Incremental Fit Index $(\mathrm{IFI}) \geq 0.09$. We followed Preacher and Hayes'[33] approach to test the mediation model and used 5,000 sample sizes recommended by Preacher and Hayes[33] in the bootstrap method.

\section{Results}

\section{Characteristics of workplace bullying, workplace spirituality and job burnout in pediatric nurses}

A total of 485 pediatric nurses were distributed online questionnaires for this survey, and 465 pediatric nurses responded and completed the questionnaire. The 63 invalid questionnaires were excluded due to obviously insufficient time to complete the survey. Finally, the data of 402 pediatric nurses were analyzed. The majority of nurses were female (97.76\%), averaging 33 years of age with 11.14 years nursing experience. The distributions of workplace bullying, workplace spirituality and job burnout in the pediatric nurses are shown in Table 1.

\section{Correlation analysis}

According to correlation analysis, we found that the workplace bullying of pediatric nurses was significantly and positively correlated to job burnout $(r=0.459, P \otimes 0.001)$. Bullying was significantly and negatively correlated to workplace spirituality $(r=\llbracket 0.187, P \otimes 0.001)$. Workplace spirituality was significantly and negatively correlated to job burnout $(r=\llbracket 0.206, P \otimes 0.001)$.

\section{Multiple linear regression analysis of the factors of job burnout among the observed pediatric nurses}

To explore factors affecting job burnout in pediatric nurses, a multiple linear regression model of the impact factors associated with job burnout was constructed. Multiple linear regression analysis was performed taking the job burnout score as a dependent variable and the statistically significant variables 
in the univariate analysis, workplace spirituality score and workplace bullying as independent variables (Table 2). The results showed that workplace bullying, and workplace spirituality were the influencing factors of job burnout in pediatric nurses.

\section{Structural equation modelling results}

The initial SEM model exhibited a reasonable fit to the data $\left(\chi^{2}=53.699, d f=24, p \otimes 0.001, \chi^{2} / d f=2.237\right.$, $\mathrm{CFI}=0.980, \mathrm{IFI}=0.980, \mathrm{RMSEA}=0.056$ ). The estimates for structural paths are shown in Table 3 , and the path coefficients for the structural equation model are shown in Figure 2. We also tested the mediating role of workplace spirituality in the relationship between workplace bullying and job burnout. The results are showed in Table 4 , both $95 \% \mathrm{Cl}(0.008,0.093)$ in indirect effect and $95 \% \mathrm{Cl}(0.502,0.863)$ in direct effect did not cross 0 , which indicated that workplace spirituality partially mediated the relationship between workplace bullying and job burnout. The ratio of mediating effect with total effect was $5.38 \%$.

\section{Discussion}

The results of this study support the proposition that workplace spirituality is associated with pediatric nurses experiencing bullying and burnout. Workplace spirituality may reduce workplace bullying and burnout by changing perceptions and evaluations of workplace bullying in pediatric nurses.

Our study showed that the score of job burnout among pediatric nurses was $2.79 \pm 1.14$, which was similar to the results of previous studies $[2,19]$. The results of multiple linear regression analysis showed that workplace bullying and workplace spirituality were influencing factors of burnout. Consistent with previous studies on workplace bullying, bullying is associated with high levels of burnout[2, 15, 34]. Continuous exposure to stressors in the workplace is an important mechanism for the development of severe burnout[35]. Bullying in the workplace is a progressive, cumulative, and highly personalized harmful experience, and it is an important factor in the occurrence of job burnout among nurses[36]. Kinjerski \& Skrypnek's[24] proposed that workplace spirituality is a positive state that includes physical, affective, cognitive, interpersonal, spiritual, and mystical dimensions. There is evidence[21] that workplace spirituality can enhance job involvement and organizational commitment, which are important in improving an organization's effectiveness and productivity and in reducing workplace deviance and turnover rate[37].

In this study, workplace bullying of pediatric nurses was at a low-moderate level, and organization-related bullying scored the highest, which is consistent with previous research results[11,38]. Nurses generally believed that they have undertaken an overloaded workload and their due rights were not guaranteed, such as statutory rest and sick leave[5]. Our research showed that nurses who had worked more years and were higher in seniority were more likely to suffer from workplace bullying, which is inconsistent with previous research results $[34,39]$. To explain the results of our study, it is necessary to understand the workplace situation for senior nurses. Firstly, senior nurses have a wealth of experience. In addition to being given routine clinical work, they also undertake multiple tasks such as teaching and management. 
They have been in a high-intensity and overloaded work environment for a long time, which is likely to cause greater psychological and work pressures[40]. Secondly, some managers may think that senior nurses are not as easy to manage as lower senior nurses, and they do not see the advantages of senior nurses. The managers may have a discriminatory attitude towards senior nurses, depriving them of their main job responsibilities, and arranging for them to perform trivial tasks that are below their level of ability[41, 42]. Therefore, hospital managers should acknowledge that workplace bullying exists, and make efforts to rationally allocate human resources, reduce nurses' work pressure, and ensure that the rights and interests of nurses are met.

The nursing profession is essentially service-oriented. Nurses often face many challenges[43], such as death of patients, public health emergencies, and work overload. Hospitals often represent an unbalanced working environment with little room for change[44]. Even with such a work environment, the workplace spirituality of pediatric nurses in this study was surprisingly high, which may be related to the nobility of their profession. Past studies have shown that there is a positive correlation between a sense of belonging and workplace spirituality[25]. In our study, for pediatiric nurses who were permanently employed by their hospitals, it was observed that the older the age and the longer the working hours, the higher their level of workplace spirituality. One possible explanation is that this situation creates a higher sense of belonging where the employees work together with the hospital to achieve a common goal[45]. Another possible explanation is that only by identifying with one's own profession, can they be dedicated to it for a long time[46]. In this study, the workplace spirituality of postgraduate nurses was significantly lower than that of associates and undergraduates, which is inconsistent with previous research results[47]. Analysis of the reason may be that nursing graduate students have a wider scope and choice of employment[48], which reduces their sense of belonging. On the other hand, it may be related to the fact that nursing graduate students have not yet adjusted their understanding of clinical nursing and the realities of the job, leading to excessive professional expectations and a reduction in the obtained professional value[49].

In Figure 2, the SEM shows that workplace bullying had a negative influence on pediatric nurses workplace spirituality and positive influence on job burnout. Workplace bullying influenced burnout indirectly through workplace spirituality, highlighting the fundamental importance of workplace bullying in pediatric nurses burnout. The mediating effect in our study reveals that workplace spirituality partially mediates the relationship between workplace bullying and job burnout. Previous studies have shown[34] that a healthy working environment is an important factor influencing nurse retention. Workplace spirituality, as a positive inner experience, is conducive to creating a good working environment and atmosphere, encouraging interpersonal communication between employees, and increasing employees' ability to understand others, thereby reducing the occurrence of uncivilized behavior in the workplace[50]. When faced with workplace bullying, workplace spirituality can help nurses to correctly recognize and evaluate stress, thereby generating positive benefits for individuals, teams, and organizations, effectively improving nurses' job involvement, physical health, job satisfaction and retention intention, and reducing work stress in the environment[51,52]. 
The results of our study reveal the internal mechanisms and impact that workplace spirituality in pediatric nurses has on bullying and job burnout. The findings support existing theories about workplace spirituality, bullying, and job burnout, and provide new information on how these concepts are interrelated to explain the job burnout of pediatric nurses. It provides new perspectives and dimensions for nursing management, which requires urgent attention from nursing managers and researchers. Nursing managers should assist in cultivating and developing the workplace spirit of pediatric nurses as part of a program to eliminate workplace bullying and reduce job burnout, so as to maintain the stability of the nursing team in the face of an extreme shortage of pediatric nurses.

\section{Strengths And Limitations}

This study is the first to report evidence suggesting that workplace spirituality may reduce the occurrence of workplace bullying in pediatric nurses. Our study also has some limitations. First, for the sake of convenience, we only sampled pediatric nurses from just one province, so the sample representation was not adequate. Second, data collection relied on self-reporting by the pediatric nurses. Therefore, we cannot guarantee that the self-reported results of each participant were accurate. Finally, our model shows the factors related to job burnout in pediatric nurses. However, we admit that there are many other factors that can explain the job burnout of pediatric nurses, which were not measured in this study. In addition to workplace spirituality, other factors such as personality characteristics and social support may also play an important role in the job burnout of pediatric nurses. These limitations should be addressed in further research.

\section{Conclusions}

Our study has contributed to the body of knowledge pertaining to mechanisms of job burnout. The results of this study highlight the importance of workplace spirituality for self-stress evaluation and cognition, which may reduce the incidence of workplace bullying, thereby reducing the job burnout of pediatric nurses.

\section{Abbreviations}

WB: Workplace bullying; WS: Workplace spirituality; JB: Job burnout; NAQ-R: Negative Acts QuestionnaireRevised; WSS: Workplace Spirituality Scale; MBI-GS: Maslach Burnout Inventory-General Survey.

\section{Declarations}

\section{Acknowledgements}

The authors thank all the pediatric nurses who participated in this study.

\section{Author Contributions}


Study conception and design: Ying Fan and Limin Xing; Data collection: Ying Fan, Mi Cao, Yumei Zhou and Peng Duan; Data analysis and interpretation: Ying Fan and Yumei Zhou; Drafting of the article: Ying Fan and Limin Xing; Critical revision of the article: Limin Xing. All the authors have carefully reviewed the article and approved the final draft.

\section{Funding}

This research received no specific grant from any funding agency in the public, commercial, or not-forprofit sectors.

\section{Availability of data and materials}

The datasets generated during and/or analysed during the current study are not publicly available due to confidentiality reason but are available from the corresponding author on reasonable request.

\section{Declarations}

\section{Ethics approval and consent to participate}

The study was approved by the Ethics Committee of Xiangyang No 1 People's Hospital Affiliated to Hubei University of Medicine and the number is 2020KY033-05. Consent was implied by completion of the survey. Individuals who did not desire to participate did not return surveys. The survey cover letter stated these facts and informed participants that their decision to take part in this study was entirely voluntary. The participants were assured to have the right to withdraw from the study without any negative effects on them. Data were being kept confidential and for research purpose only. All methods were carried out in relevant regulations and guidelines.

\section{Consent for publication}

Not applicable.

\section{Competing interests}

The authors declared no potential conflicts of interest with respect to the research, authorship, and/or publication of this article.

\section{Author details}

${ }^{1}$ Xiangyang No 1 People's Hospital Affiliated to Hubei University of Medicine, No.15 JieFang Road, Fancheng District, Xiangyang 441000, Hubei Province, China. ${ }^{2}$ Wuhan University School of Health Sciences, No. 115 Donghu Road, Wuchang District, Wuhan 430071, Hubei Province, China.

\section{Reference}


1. Kivimäki M, Elovainio M, Vahtera J. Workplace bullying and sickness absence in hospital staff. Occup Environ Med. 2000;57(10):656-660. DOI: 10.1136/oem.57.10.656.

2. Kim Y, Lee E, Lee H. Association between workplace bullying and burnout, professional quality of life, and turnover intention among clinical nurses. PloS one. 2019;14(12):e0226506. DOI:

10.1371/journal.pone.0226506

3. The hospital tyrants and their victims, the nurses: What doctors say of the oppression of young women in these institutions. The New York Times. 1909; August 22: SM8.

4. Teo STT, Nguyen D, Trevelyan F, Lamm F, Boocock M. Workplace bullying, psychological hardiness, and accidents and injuries in nursing: A moderated mediation model. PloS one. 2021;16(1):e0244426. DOl: 10.1371/journal.pone.0244426.

5. Chen $\mathrm{J}$ and Zheng YL. Workplace bullying and its influencing factors among clinical nurses. Journal of Nursing Science 2020; 35(7): 62-65. DOI: 10.3870/j.issn.1001-4152.2020.07.062.

6. Ramsdell KD, Morrison M, Kassam-Adams N, Marsac ML. A Qualitative Analysis of Children's Emotional Reactions During Hospitalization Following Injury. J Trauma Nurs. 2016;23(4):194-201. DOI: 10.1097/jtn.0000000000000217.

7. Marques G. The family of the child with cancer: socioeconomic needs. Rev Gaucha Enferm. 2017;38(4):e2016-2078. DOI: 10.1590/1983-1447.2017.04.2016-0078.

8. Katz LF, Fladeboe K, King K, Gurtovenko K, Kawamura J, Friedman D, et al. Trajectories of child and caregiver psychological adjustment in families of children with cancer. Health Psychol. 2018;37(8):725735. DOI: $10.1037 /$ hea0000619.

9. Pan JH, Yan FF, Liu YW, Liu LJ, Zhang Y, Pan QX, et al. Survey of occurrence and report status quo of pediatric nurses suffering workplace violence in hospital. Chinese Nursing Research. 2018;32(01):84-89. DOI: 10.3969凶j.issn.10096493.

10. Chen ZH, Lin JR, Sun SY. Analysis of epidemiological features of workplace violence experiences among nurses in pediatrics department. Modern Preventive Medicine. 2011;38(10):1810-1811.

11. Lin YP, Qiu JH, Lin N, Zheng XY, Fang DP, Gao R. Mediating effect of peer support among nurses in the relationship between workplace bullying and job satisfaction. Chinese Journal of Modern Nursing. 2017;23(24):3093-3097. DOI: 10.3760/cma.j.issn

12. Sauer PA, McCoy TP. Nurse Bullying: Impact on Nurses' Health. West J Nurs Res. 2017;39(12):15331546. DOI: $10.1177 / 0193945916681278$.

13. Laschinger HK, Grau AL, Finegan J, Wilk P. New graduate nurses' experiences of bullying and burnout in hospital settings. J Adv Nurs. 2010;66(12):2732-2742. DOI: 10.1111/j.1365-2648.2010.05420.x. 
14. Hamre KV, Einarsen SV, Hoprekstad $\varnothing$ L, Pallesen S, Bjorvatn B, Waage S, et al. Accumulated LongTerm Exposure to Workplace Bullying Impairs Psychological Hardiness: A Five-Year Longitudinal Study among Nurses. Int J Environ Res Public Health. 2020;17(7). :2587. DOI: 10.3390/ijerph17072587.

15. Yun S, Kang J. Influencing Factors and Consequences of Workplace Bullying among Nurses: A Structural Equation Modeling. Asian Nurs Res. 2018;12(1):26-33. DOI: 10.1016/j.anr.2018.01.00

16. Laschinger HK. Impact of workplace mistreatment on patient safety risk and nurse-assessed patient outcomes. J Nurs Adm. 2014;44(5):284-290. DOI: 10.1097/nna.0000000000000068.

17. Che C, Zhang J, Jia M. An empirical study of the influencing mechanism of stretch goals over emotional exhaustion: Based on transactional theory of stress. Journal of Industrial Engineering and Engineering Management. 2019;33(3):1-8. DOI: 10.13587/j.cnki.jieem.2019.03.001.

18. Folkman S, Lazarus RS, Dunkel-Schetter C, DeLongis A, Gruen RJ. Dynamics of a stressful encounter: cognitive appraisal, coping, and encounter outcomes. J Pers Soc Psychol. 1986;50(5):992-1003. DOI: 10.1037//0022-3514.50.5.992.

19. Zhou X, Li XM, Yin LYT, Zhang N, Li Y, Xiang YL.Studying on the Impact of Patients' Mistreatment on Nurses' Job Burnout and Intention to Demission. Chinese Health Service Management. 2017;34(7):543545.

20. Oyeleye O, Hanson P, O'Connor N, Dunn D. Relationship of workplace incivility, stress, and burnout on nurses' turnover intentions and psychological empowerment. J Nurs Adm. 2013;43(10):536-542. DOI: 10.1097/NNA.0b013e3182a3e8c9.

21. Pirkola H, Rantakokko P, Suhonen M. Workplace spirituality in health care: an integrated review of the literature. J Nurs Manag. 2016;24(7):859-868. DOI: 10.1111/jonm.12398.

22. Xuan XY, Zhang JW, Li HH,Zhou J, Zhou YF. Proactive Behavior of R\&D Personnel in Military Industry under the Dual Path of Work Stress:The Moderating Effect of Workplace Spirituality. Science \& Technology Progress and Policy. 2020;37(20):135-144. DOI: 10.6049/kjjbydc.Q201908968.

23. Zhang TQ, Zhang YJ, Chen WX. Research on the Influence of Workplace Spirituality on Harmonious Labor Relations. Human Resource Development of China. 2017(06):146-154. DOI: 10.16471/j.cnki.112822/c.2017.06.017.

24. Dal Corso L, De Carlo A, Carluccio F, Colledani D, Falco A. Employee burnout and positive dimensions of well-being: A latent workplace spirituality profile analysis. PloS one. 2020;15(11):e0242267. DOI: 10.1371/journal.pone.0242267.

25. Van der Walt F, de Klerk JJ. Workplace spirituality and job satisfaction. Int Rev Psychiatry. 2014;26(3):379-389. DOI: 10.3109/09540261.2014.908826. 
26. Einarsen S, Hoel H, Notelaers G. Measuring Exposure to Bullying and Harassment at Work: Validity, Factor Structure and Psychometric Properties of the Negative Acts Questionnaire-Revised. Work Stress. 2009;23:24-44. DOI: 10.1080/02678370902815673.

27. Xun HJ, Liu HX, Tian ZL. A Preliminary reliability and validity study of the Chinese version of the Negative Acts Questionnaire revised. Chinese Nursing Management. 2012;12(6):21-24. DOI: 10.3969/j.issn.1672-1756.2012.06.006.

28. Ke JL, Sun JM, Wang J. Development and Validation of the Workplace Spirituality Scale. Chinese Journal of Clinical Psychology. 2014;22(5):826-830.

29. Maslach C, Schaufeli WB, Leiter MP. Job burnout. Annual review of psychology. 2001;52:397-422 DOI: 10.1146/annurev.psych.52.1.397.

30. Li CP, Shi K, Luo ZX, Li L, Yang Y. An Investigation on Job Burnout of Doctor and Nurse. Chinese Journal of Clinical Psychology. 2003;11(3):170-172. DOI: 10.3969/j.issn.1005-3611.2003.03.004.

31. Zhu W, Lou XP, Wang ZM. MaslashThe study of construct validity and reliability of the Maslach burnout inventory-general survey (MBI-GS) for nurses Maslash. Chinese Behavioral Medicine Science. 2007;16(9):849-851. DOI: 10.3760/cma.j.issn.1674-6554.2007.09.031.

32. McDonald RP, Ho MH. Principles and practice in reporting structural equation analyses. Psychol Methods. 2002;7(1):64-82. DOI: 10.1037/1082-989x.7.1.64.

33. Preacher KJ, Hayes AF. Asymptotic and resampling strategies for assessing and comparing indirect effects in multiple mediator models. BBehav Res Methods. 2008;40(3):879-891. DOI: 10.3758/brm.40.3.879.

34. Spence Laschinger HK, Wong CA, Grau AL. The influence of authentic leadership on newly graduated nurses' experiences of workplace bullying, burnout and retention outcomes: a cross-sectional study. Int J Nurs Stud. 2012;49(10):1266-1276. DOI: 10.1016/j.ijnurstu.2012.05.012.

35. Maslach C, Leiter, M.P., . The Truth About Burnout: How Organizations Cause Personal Stress and What to Do About it. Jossey-Bass, San Francisco, CA. 1997.

36. Etienne E. Exploring workplace bullying in nursing. Workplace Health Saf. 2014;62(1):6-11. DOI: $10.1177 / 216507991406200102$.

37. Amin S, Adriani Z, Khaeruddin, Habibi A. DATASET for validation the relationship between workplace spirituality, organizational commitment, and workplace deviance. Data Brief. 2020;31:105872. DOI: 10.1016/j.dib.2020.105872.

38. Chen PP, Re YF, Zheng XM, Hou M, Wang XL, Zhang XM, et al. Association between workplace bullying and emotional intelligence in nurses. Journal of Nursing Science. 2021;36(19):69-72. DOI: 
39. Xun JH. A study on the correlation between workplace depression and job satisfaction and job burnout of clinical nurses. Taishan Medical College; 2011.

40. Luan X, Wang P, Hou W, Chen L, Lou F. Job stress and burnout: A comparative study of senior and head nurses in China. Nurs Health Sci. 2017;19(2):163-169. DOI: 10.1111/nhs.12328.

41. Zhang ZX, Shang LP. Analysis of pofessional development of senior nurses and its influencing factors. Chinese Nursing Research. 2015(33):4206-4209. DOI: 10.3969/j.issn.1009-6493.2015.33.043.

42. Wang P, Sun XF, Ren YB, Yi XR. Survey and strategies on the job stressors and burnout of senior nurses. Chin J Prac Nurs. 2016;32(24):1898-1902. DOI: 10.3760/cma.j.issn.1672-7088.2016.24.017.

43. Arnetz JE, Goetz CM, Arnetz BB, Arble E. Nurse Reports of Stressful Situations during the COVID-19 Pandemic: Qualitative Analysis of Survey Responses. Int J Environ Res Public Health. 2020;17(21). DOI: 10.3390/ijerph17218126.

44. Hayashi R, Fujita S, lida S, Nagai Y, Shimamori Y, Hasegawa T. Relationship of patient safety culture with factors influencing working environment such as working hours, the number of night shifts, and the number of days off among healthcare workers in Japan: a cross-sectional study. BMC Health Serv Res;20(1):310. DOI: 10.1186/s12913-020-05114-8.

45. Zhang TQ, Zhang TQ, Zhang YJ. Research on the Influence of Workplace Spirituality on Harmonious Labor Relations. Human Resource Development of China. 2017(6):146-154. DOI: 10.3969/j.issn.10044124.2017.06.017.

46. Niskala J, Kanste O, Tomietto M, Miettunen J, Tuomikoski AM, Kyngäs $\mathrm{H}$, et al. Interventions to improve nurses' job satisfaction: A systematic review and meta-analysis. J Adv Nurs. 2020;76(7):14981508. DOI: $10.1111 /$ jan.14342.

47. Ke LJ, Jiang Yf and Qiu XW. The Influence of Mental Intelligence on Workplace Spirituality--The Moderating Effect of Organizational Support and Family Support. Research on Economics and Management. 2017;38(6):54-65. DOI: 10.13502/j.cnki.issn1000-7636.2017.06.006.

48. Wang L, Cheng YJ, Liu SZ. Analysis of employment direction of master degree nursing postgraduates. Chinese Nursing Research. 2010;24(24):2192-2194. DOI: 10.3969/j.issn.1009-6493.2010.24.015.

49. Li H, Shi MX, Lu LF, Guo QL, Qiao SS. Analysis of status quo of employment satisfaction status and its influencing factors among postgraduates with nursing professional degree in Shanxi province from 2014 to 2019. Chinese Nursing Research. 2020;34(14):2529-2534. DOI: 10.12102/j.issn.10096493.2020.14.019. 
50. Phillips GS, MacKusick $\mathrm{Cl}$, Whichello R. Workplace Incivility in Nursing: A Literature Review Through the Lens of Ethics and Spirituality. J Christ Nurs. 2018;35(1):e7-e12. DOI:

10.1097/cnj.0000000000000467.

51. Kazemipour F, Mohamad Amin S, Pourseidi B. Relationship between workplace spirituality and organizational citizenship behavior among nurses through mediation of affective organizational commitment. J Nurs Scholarsh. 2012;44(3):302-310. DOI: 10.1111/j.1547-5069.2012.01456.x.

52. Schneider KT, DeSouza ER, Durst RN. Links Between Workplace Spirituality, Job-Related Attitudes, and Value Fit in a Non-Profit Agency. J Prev Interv Community. 2015;43(3):199-210. DOI:

10.1080/10852352.2014.973283.

\section{Tables}

Table 1 Demographic information of the study participants and the distributions of workplace bullying, workplace spirituality, job burnout by observed variables 


\begin{tabular}{|c|c|c|c|c|}
\hline \multirow[t]{2}{*}{ Variable } & \multirow[t]{2}{*}{$n(\%)$} & WB & WS & JB \\
\hline & & Mean $\pm S D$ & Mean $\pm S D$ & Mean $\pm S D$ \\
\hline \multicolumn{5}{|l|}{ Gender } \\
\hline Male & $9(2.24)$ & $1.85 \pm 0.70$ & $2.12 \pm 0.52$ & $2.80 \pm 1.32$ \\
\hline Female & 393(97.76) & $1.72 \pm 0.47$ & $2.87 \pm 0.48$ & $2.79 \pm 1.14$ \\
\hline$p$ & & 0.586 & $\nabla 0.001^{* * *}$ & 0.985 \\
\hline$t$ & & 0.567 & -4.601 & 0.019 \\
\hline \multicolumn{5}{|l|}{ Age } \\
\hline$\leq 30$ & $180(44.78)$ & $1.67 \pm 0.43$ & $2.80 \pm 0.46$ & $2.75 \pm 1.67$ \\
\hline $31 \varangle 40$ & 154(38.31) & $1.70 \pm 0.42$ & $2.84 \pm 0.53$ & $2.97 \pm 1.17$ \\
\hline$\geq 41$ & 68(16.91) & $1.92 \pm 0.62$ & $2.99 \pm 0.50$ & $2.50 \pm 0.94$ \\
\hline$p$ & & $0.001 * *$ & $0.027^{*}$ & $0.015^{*}$ \\
\hline$F$ & & 7.556 & 3.653 & 4.268 \\
\hline \multicolumn{5}{|l|}{ Marital status } \\
\hline Single & $109(27.11)$ & $1.70 \pm 0.46$ & $2.79 \pm 0.47$ & $2.95 \pm 1.18$ \\
\hline Married & 293(72.89) & $1.73 \pm 0.49$ & $2.87 \pm 0.50$ & $2.73 \pm 1.12$ \\
\hline$p$ & & 0.562 & 0.122 & 0.083 \\
\hline$t$ & & -0.580 & -1.550 & 1.735 \\
\hline \multicolumn{5}{|c|}{ Years of Experience } \\
\hline$\leq 5$ & 126(31.34) & $1.64 \pm 0.44$ & $2.80 \pm 0.43$ & $2.71 \pm 1.19$ \\
\hline $6 \bigotimes 10$ & $103(25.62)$ & $1.70 \pm 0.39$ & $2.82 \pm 0.50$ & $2.87 \pm 1.09$ \\
\hline $11 \otimes 15$ & $99(24.63)$ & $1.76 \pm 0.48$ & $2.82 \pm 0.54$ & $3.06 \pm 1.23$ \\
\hline$\geq 16$ & 74(18.41) & $1.86 \pm 0.60$ & $3.01 \pm 0.50$ & $2.46 \pm 0.91$ \\
\hline$p$ & & $0.012^{*}$ & $0.017^{*}$ & $0.005^{\star *}$ \\
\hline$F$ & & 3.676 & 3.438 & 4.384 \\
\hline \multicolumn{5}{|l|}{ Employment type } \\
\hline Permanent nurse & 78(19.40) & $1.79 \pm 0.53$ & $3.00 \pm 4.81$ & $2.51 \pm 1.00$ \\
\hline Contract nurse & $324(80.60)$ & $1.71 \pm 0.46$ & $2.81 \pm 0.49$ & $2.86 \pm 1.17$ \\
\hline$p$ & & 0.158 & $0.002 * *$ & $0.008 * *$ \\
\hline
\end{tabular}




\begin{tabular}{|lllll|}
\hline$t$ & & 1.415 & 9.382 & -2.705 \\
\hline Education & & & & \\
sechnical secondary & $6(1.49)$ & $2.03 \pm 0.86$ & $2.72 \pm 0.61$ & $1.90 \pm 0.84$ \\
\hline Junior college & & & & \\
\hline Undergraduate & $47(11.69)$ & $1.72 \pm 0.54$ & $2.87 \pm 0.41$ & $2.61 \pm 1.05$ \\
\hline Postgraduate & $329(81.84)$ & $1.71 \pm 0.44$ & $2.86 \pm 0.50$ & $2.81 \pm 1.14$ \\
\hline$p$ & $20(4.98)$ & $1.91 \pm 0.65$ & $2.66 \pm 0.58$ & $3.12 \pm 1.32$ \\
\hline$F$ & & 0.115 & 0.329 & 0.090 \\
\hline Title & & 1.986 & 1.150 & 2.179 \\
\hline Nurses & & & & \\
\hline Senior nurses & & & & \\
\hline Supervisor nurses & $17(21.15)$ & $1.67 \pm 0.44$ & $2.80 \pm 0.45$ & $2.69 \pm 1.13$ \\
\hline Deputy chief nurse or above & $26(6.47)$ & $1.87 \pm 0.61$ & $3.21 \pm 0.47$ & $2.51 \pm 0.75$ \\
\hline$p$ & & 0.090 & $0.001 * *$ & 0.289 \\
\hline$F$ & $174(43.28)$ & $1.69 \pm 0.39$ & $2.83 \pm 0.45$ & $2.90 \pm 1.21$ \\
\hline Shift type & & 2.181 & 5.280 & 1.256 \\
\hline Day shift & & & & \\
\hline Three shift & & -1.320 & 2.331 & -2.430 \\
\hline$p$ & $240(59.70)$ & $1.75 \pm 0.44$ & $2.80 \pm 0.50$ & $2.90 \pm 1.19$ \\
\hline$t$ & & & & \\
\hline
\end{tabular}

Note. $N=402 ;{ }^{*} P \otimes 0.05,{ }^{*} P \otimes 0.01,{ }^{* * * P \otimes 0.001 ; S D=S t a n d a r d ~ D e v i a t i o n ; ~ W B: ~ W o r k p l a c e ~ b u l l y i n g ; ~ W S: ~}$ Workplace spirituality; JB: Job burnout

Table 2 Results of multiple stepwise linear regression analysis of the factors of job burnout in the pediatric nurses 


\begin{tabular}{|lllllll|}
\hline & B & $\begin{array}{l}\text { Std.Error } \\
\text { (SE) }\end{array}$ & Beta & $t$ & $95 \% \mathrm{Cl}$ & $P$ \\
\hline Age & 0.016 & 0.025 & 0.104 & 0.648 & $(-0.033,0.066)$ & 0.517 \\
\hline Years of experience & -0.022 & 0.022 & -0.163 & -1.002 & $(-0.065,0.021)$ & 0.317 \\
\hline $\begin{array}{l}\text { Employment type: Contract } \\
\text { nurse }\end{array}$ & 0.288 & 0.158 & 0.100 & 1.824 & $(-0.022,0.599)$ & 0.069 \\
\hline Shift type: Three shift & 0.031 & 0.119 & 0.013 & 0.260 & $(-0.203,0.264)$ & 0.795 \\
\hline Workplace bullying & 1.107 & 0.113 & 0.459 & 9.795 & $(0.885,1.329)$ & 0 \\
\hline Workplace spirituality & -0.221 & 0.105 & -0.096 & -2.108 & $(-0.427$, & 0.001 \\
\hline
\end{tabular}

Note. $N=402 ;{ }^{*} P \otimes 0.05, * * P \otimes 0.001$.

Table 3 Effect estimates for hypothesized structural paths

\begin{tabular}{|lllclc|}
\hline $\begin{array}{l}\text { Structural } \\
\text { paths }\end{array}$ & $\begin{array}{l}\text { Unstandardized } \\
\text { coefficients }\end{array}$ & $\begin{array}{l}\text { standardized } \\
\text { coefficients }\end{array}$ & SE & $\begin{array}{l}\text { Critical } \\
\text { ratio }\end{array}$ & $P$ \\
\hline$W B \rightarrow$ WS & -0.173 & -0.215 & 0.048 & -3.616 & $\square$ \\
\hline$W S \rightarrow J B$ & -0.323 & -0.137 & 0.129 & -2.510 & 0.012 \\
\hline$W B \rightarrow J B$ & 0.963 & 0.510 & 0.119 & 8.122 & 0.001 \\
\hline
\end{tabular}

Note. SE = standard error

Table 4 Mediating Model and the mediation effect of workplace spirituality

\begin{tabular}{|lllll|}
\hline & Effect & SE & $P$ & $95 \% \mathrm{Cl}$ \\
\hline Indirect effect & 0.029 & 0.021 & 0.009 & $(0.008,0.093)$ \\
\hline Direct effect & 0.510 & 0.093 & $\bigotimes 0.001$ & $(0.502,0.863)$ \\
\hline Total effect & 0.539 & 0.093 & $\bigotimes 0.001$ & $(0.542,0.908)$ \\
\hline
\end{tabular}

\section{Figures}




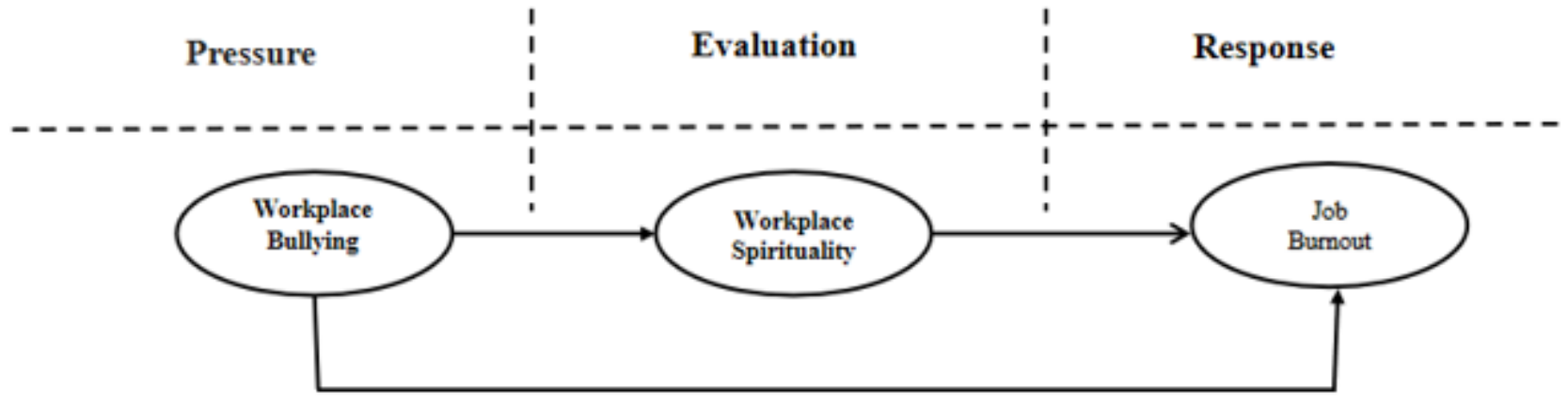

\section{Figure 1}

Hypothesized study model

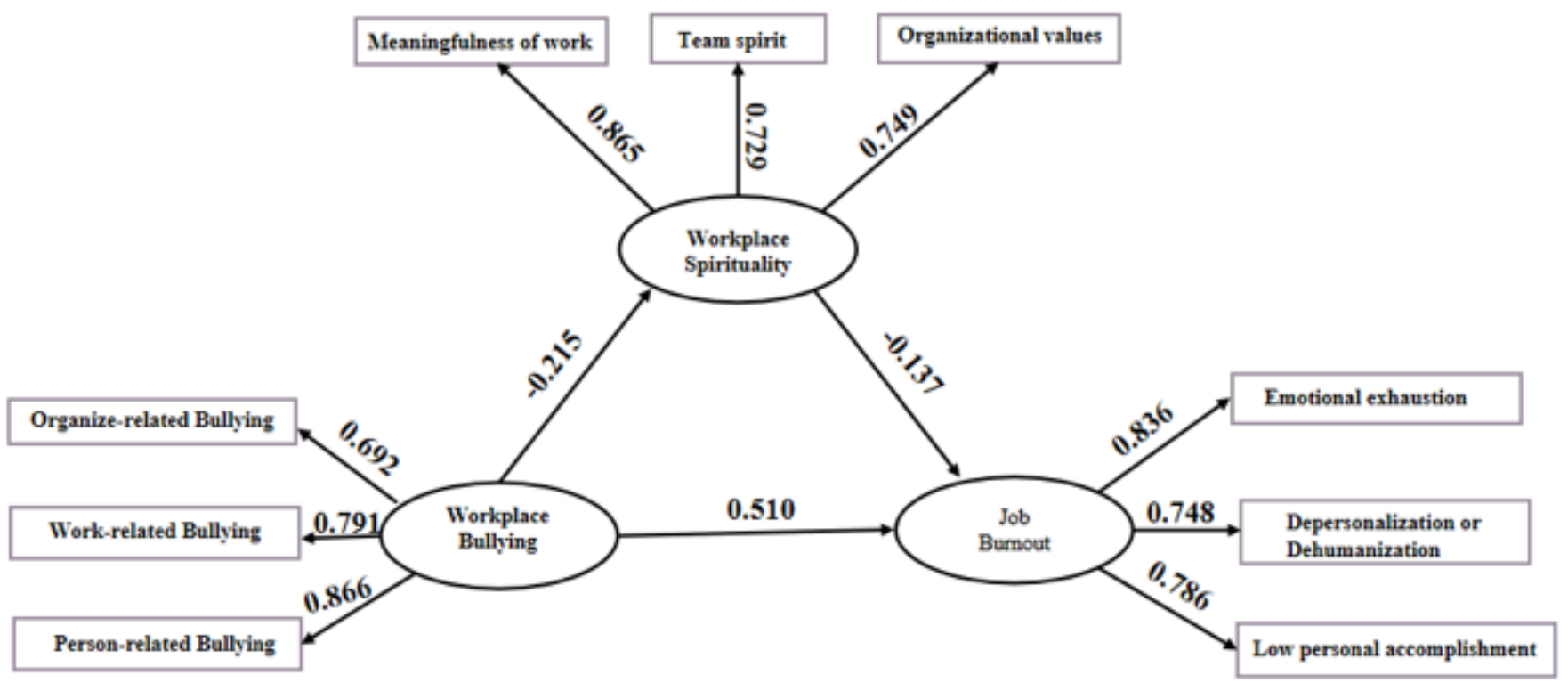

Figure 2

Path coefficient of structural equation model (Standardized coefficients) 